\title{
The role of Cultural Gathering Spaces in the Promotion of Citizen Quality of Life Case study: Tehran City Theater
}

\author{
Behnam Ghasemzadeh ${ }^{\mathrm{A}}$, Sahar Toofan ${ }^{\mathrm{A}}$ \\ Received: November 14, 2013 | Revised: January 11, 2014 | Accepted: February 15, 2014
}

\begin{abstract}
A city as a context of urban human life requires meeting some standards which at a glance are called the standards of life quality. In fact, the quality of life is a complex and multi-dimensional concept. Measuring the quality of life in Iran, according to particular social, economic and cultural conditions of this country and also the emphasis of country twenty years visions on this issue, has special importance. Cultural gathering spaces improve social and economic vitality in one side and in other side provide favorable conditions for citizen leisure. Theatres are one of cultural complexes which have important role in the promotion of citizens' quality of life. What is today known as Tehran City Theatre is a beautiful circular cylindrical building which is located at Daneshjoo park ,Vali-e-Asr crossroad, Tehran city; and for some reasons daily attracts hundreds of people. The objective of this study is to explain the role of City Theatre in promoting citizens' quality of life. Research method is analytical descriptive. Data collection method has been based on researcher's objective assessments and filling questionnaire. Cochran's formula was used to determine sampling volume and questionnaires were distributed among citizens of district 11, Tehran city; then 480 questionnaires gathered and analyzed. The research findings show that City Theatre has an effective and positive role on mental dimension of citizens' quality of life. The capabilities of this collection can be increased for citizens' quality of life by creating facilities such as transportation control and avoiding interference of riding and pedestrian, creating sitting and pause spaces in this collection, and spaces associated with this collection using.
\end{abstract}

Keywords: Cultural spaces, gathering spaces, quality of life, Tehran City Theatre

\section{Introduction}

Currently, more than half of world's population live in urban area and by 2020 this figure will reach to $60 \%$; so, urbanization phenomenon has become an inevitable work. Human habitat can provide the most desirability for human when it meets his/her expectations (Kakavand et al., 2013). Responding to human social and cultural needs and supplying the necessary opportunities to gain social experiences require the existence of spaces and physical settlements (Charkhian, Daneshpour, 2009). But what makes these spaces socially active; at first are physical factors that can underlie for individuals' entry and then stop within the space. Anticipation and creation of social events while creating opportunities to participate in social activities can ground the promotion and dependency to the location (Lennard, 1984; Piran, 2001).

Cultural spaces ground individuals' presence in the city ( Bakhtiar, Nasrabadi, 2011), provide social interactions and reactions, and create a shared collective memory, sense of dependency to space and quality control of the urban landscape (Charkhian, Daneshpour, 2007; Yazdani, Lavasani, 2010). Surveying the importance of cultural and gathering spaces in the city structure, it becomes clear that cultural and gathering spaces take place with interactive dialogue among citizens in the form of face to face meeting and holding presentation, social and cultural cer-

A Department of Architecture, Tabriz branch, Islamic Azad University, Tabriz, Iran

* Corresponding author: Behnam Ghasemzadeh, behnam.ghasemzadeh@yahoo.com 
emony (Mirmoghtadaie, 2009); and today they are remarkable as one of the fundamental characteristics in new urbanism idea. The shortage of such spaces is obvious in Tehran. City Theatre may be today counted as a few examples of successful cultural gathering spaces in Iran (Rafieyan, Razavi, 2010). Unfortunately, cultural gathering spaces in Iran have been less exploited for promotion and strengthening of urban life. Research findings can provide useful information for planning of development and the strategies that promote citizens quality of life. Hence, this paper studied City Theatre with the aim of investigating the role of cultural gathering spaces in the promotion of citizens' quality of life.

\section{Theoretical basis and concepts}

\section{Quality of life}

One of the most important streams of thoughts that influence on urban planning has been the concept of urban quality of life (Kokabi, et al., 2005). The quality of life in urban areas is considered as comfortable life and access to basic needs in an urban environment (Eiser, 2004). The quality of life may be a good sense that results from a combination of factors associated with the sense of location or location identity such as legibility, collective memory and the sense of historical dependency (Profect, Power,1992; Khastoo, Saeedi Rezvani, 2010). Most scholars and experts believe that the quality of life has physical-environmental, social, psychological, environmental and economic dimensions ( $\mathrm{Fa}-$ tahi, 2008). Measuring the quality of urban life (Jajarmi, Kalteh, 2006) has been conducted based on four key indicators of urban life each contains many variables in order to measure the grades exactly (Table 1).

Octoploid dimensions constituting the concept of quality of life were determined in an analysis which was conducted by Shalook (2006) according to the study of 9749 articles abstracts, 2455 articles and 897 deep studies of article using the most accurate crite- ria and due to empirical basis and using authors' reference to one or more special dimensions of the quality of life.

\section{Environmental culture-city}

City cannot be merely defined as a place for living a group of people together, because this definition is also true for human gathering habitats in pre-civilization and even pre- historic periods (Piran, 2001). Cultural development is prerequisite for each development. Development is not possible without achieving its special culture (Moradi, 2010). According to the same point, the category of cultural spaces of the city obtained by adding civilization to buildings construction, living places and social interaction of people; so that material needs including cultural needs of the community are supplied (Pakzad, 2001; Fani, 2009). Because civilization is essentially founded on the idea, culture, individual and social rights and other categories like that, which are subjective affairs and independent of material concept of living place. Culture is a part of environment which is manipulated by human (Kaffashi, 2008). Culture includes all the factors that individual has unconsciously affected by them; human groups, or techniques and various methods, social institutions, beliefs and different forms of contact and etc. (Gharb, 2001). Culture is a tool for adaptation with environment. Culture is not static but mobile and dynamic. Changes occur in evolution way and their song is different in different societies. Financial and spiritual investment can be thought at the macro level for long-term cultural output and deeper and more positive influence on citizens mind in order to further flourishing of potential powers and creativity existing in different generations of the community (Imani Jajarmi, 2001; Ghasemzadeh, 2012; Mohammadi, Izadi, 2013).

\section{Spaces and cultural activities}

To achieve progress and development, nations require recognizing their history, and in the present era cultural complexes include a part of heritages and relics relat-

Table 1. Key indicators of urban life

\begin{tabular}{|c|c|c|}
\hline Indicators & Variables & References \\
\hline Social and aesthetic & $\begin{array}{l}\text { Social or public security, Spaces for leisure, Pedestrian } \\
\text { spaces, Green and open spaces, Spatial order, } \\
\text { Perspective sequence, legibility, Visibility, Spatial } \\
\text { perception }\end{array}$ & \multirow{4}{*}{$\begin{array}{l}\text { (Mukherjee,1989), (May,1996), ), } \\
\text { (Ibrahim, Chung, 2003), (Ventegots, } \\
\text { Jovvj, 2003) (Schalock, 2004), } \\
\text { (Abbaszadegan, 2005), (Kokabi et } \\
\text { al., 2005), (Golkar, 2007), (Rabbani } \\
\text { Khorasgani, Kianpour, 2007), (Kokabi, } \\
\text { 2007), (Nejat, 2008), (Noghani, et } \\
\text { al., 2008), (Faraji Molaei, et al., 2010), } \\
\text { (Ghorbani and Teimouri, 2010), (Rafiean, } \\
\text { Razavi, 2010), (Hajinejad, et al., 2011), } \\
\text { (Ghasemzadeh, 2012), (Ghasemzadeh } \\
\text { and Toofan, 2013), (Mousavi et al., 2013) }\end{array}$} \\
\hline Economic & $\begin{array}{l}\text { Supplying initial resources, Purchasing power, } \\
\text { Residential land values, Job satisfaction }\end{array}$ & \\
\hline Physical & $\begin{array}{l}\text { Habitable space, Major housing facilities, Housing } \\
\text { ownership, Number of rooms, Building arrangement }\end{array}$ & \\
\hline $\begin{array}{l}\text { Communication and } \\
\text { Transportation }\end{array}$ & $\begin{array}{l}\text { Communications tools, Public transportation, Traffic } \\
\text { flow, Satisfaction of inner-city tours }\end{array}$ & \\
\hline
\end{tabular}


The role of Cultural Gathering Spaces in the promotion of citizen quality of life

Case study: Tehran City Theater

Table 2. Dimensions constituting the concept of quality of life

\begin{tabular}{|c|c|}
\hline Octoploid dimensions constituting the concept of quality of life & Indicator and descriptive \\
\hline Emotional Well-being & $\begin{array}{l}\text { 1.Satisfied (satisfaction, moods, enjoy) } \\
\text { 2. Self - concepts (identity, self-worth, self-esteem) } \\
\text { 3. Lack of stress (predictability, control) }\end{array}$ \\
\hline Interpersonal Relations & $\begin{array}{l}\text { 1.Interactions (social networks, social contacts) } \\
\text { 2. Relationships (family, friends, peers) } \\
\text { 3.Supports (emotional, physical, financial, feedback) }\end{array}$ \\
\hline Material Well-being & $\begin{array}{l}\text { 1.Financial base (revenue, profit) } \\
\text { 2. Employment status (job status, work environment) } \\
\text { 3.Housing (type of residence, ownership) }\end{array}$ \\
\hline Personal Development & $\begin{array}{l}\text { 1. Education (achievements, academic base) } \\
\text { 2. Individual competence (cognitive, social, practical) } \\
\text { 3.Performance (success, achievement, efficiency) }\end{array}$ \\
\hline Physical Well-being & $\begin{array}{l}\text { 1. Health (functional, symptoms, fitness, nutrition) } \\
\text { 2.Daily physical activities (self-care skills, mobility) } \\
\text { 3. Leisure (entertainment, hobby) }\end{array}$ \\
\hline Self-determination & $\begin{array}{l}\text { 1. Independency / self-control (lack of dependency) } \\
\text { 2.Personal goals and values (wishes and expectations) } \\
\text { 3.Selections (opportunities, alternatives, preferences) }\end{array}$ \\
\hline Social inclusion & $\begin{array}{l}\text { 1. Participation and integration in the community } \\
\text { 2. Social roles ( donor, volunteers) } \\
\text { 3. Social supports (support networks, services) }\end{array}$ \\
\hline Rights & $\begin{array}{l}\text { 1. Human rights (respect, dignity, equality) } \\
\text { 2. Legal rights (citizenship, enjoyment, process) }\end{array}$ \\
\hline
\end{tabular}

Source: Schalock, 2006

ed to the past. A significant part of culture returns to the country monuments, those which perhaps include contemporary history in which type of life shows the tools of each period of history and each of them have a cultural manifestation (Tweed, Sutherland, 2007). Spaces, social, cultural and service centers in the city are created followed by social needs and activities and to supply them (Kaffashi, 2008; Rafieian, Razavi, 2010). In other words, a social or cultural center is a place for gathering and integrating the components of needs and activities in order to make them physical or run them in the frame work of physical spaces and continue social life of urban community (Daneshpour, Charkhian, 2007; Yazdani, Lavasani, 2010; Ghsemzadeh, Toofan, 2013). Accordingly, all social needs of city residents and the necessity of integration and making them physical to establish social life of urban community should be analyzed in detail (Karen, 2002; Kashanijoo, 2010; Fazeli, 2012) and appropriate contexts to be provided for creating social spaces. Appropriate recognition of activity spaces and locations in spatial and physical design relies on this trend. Social and cultural spaces of urban community are the place of supply and demand for activities, and spatial reflex of social supply and demand (Parsi, 2002; Ghasemzadeh, 2012).

\section{City Theatre}

This building is located at the intersection of Vali-eAsr and Islamic revolution streets, in the southwest corner of Daneshjoo park. This cylindrical building has a diameter of approximate $34 \mathrm{~m}$ and a height of 15 $\mathrm{m}$, its exterior facing all covered with turquoise tiles and a stoic with extended pillars and trefoil star base covering it around, the curved beams have kept the protruded ceiling of the building (Naghsh consulting engineers, 2008). Where professional play works of Iran theatre staged in its halls by famous directors and actors (Figure 1) (Yazdani, Lavasani, 2010).

\section{Hypotheses}

1. City Theatre has played an important role on the promotion of the quality of citizens' life.

2. City Theatre has played an important role in citizens' satisfaction feeling of life.

3. City Theatre has played an important role in citizens' happiness and joy feeling of life.

4. City Theatre has played an important role in citizens' leisure.

\section{Methodology}

The present research is descriptive and explanatory, and survey method is used to conduct it. The research that is conducted in order to make positive alterations is developmental research, and also practical because it is useful and can be used for several urban organizations like municipality. Documen- 

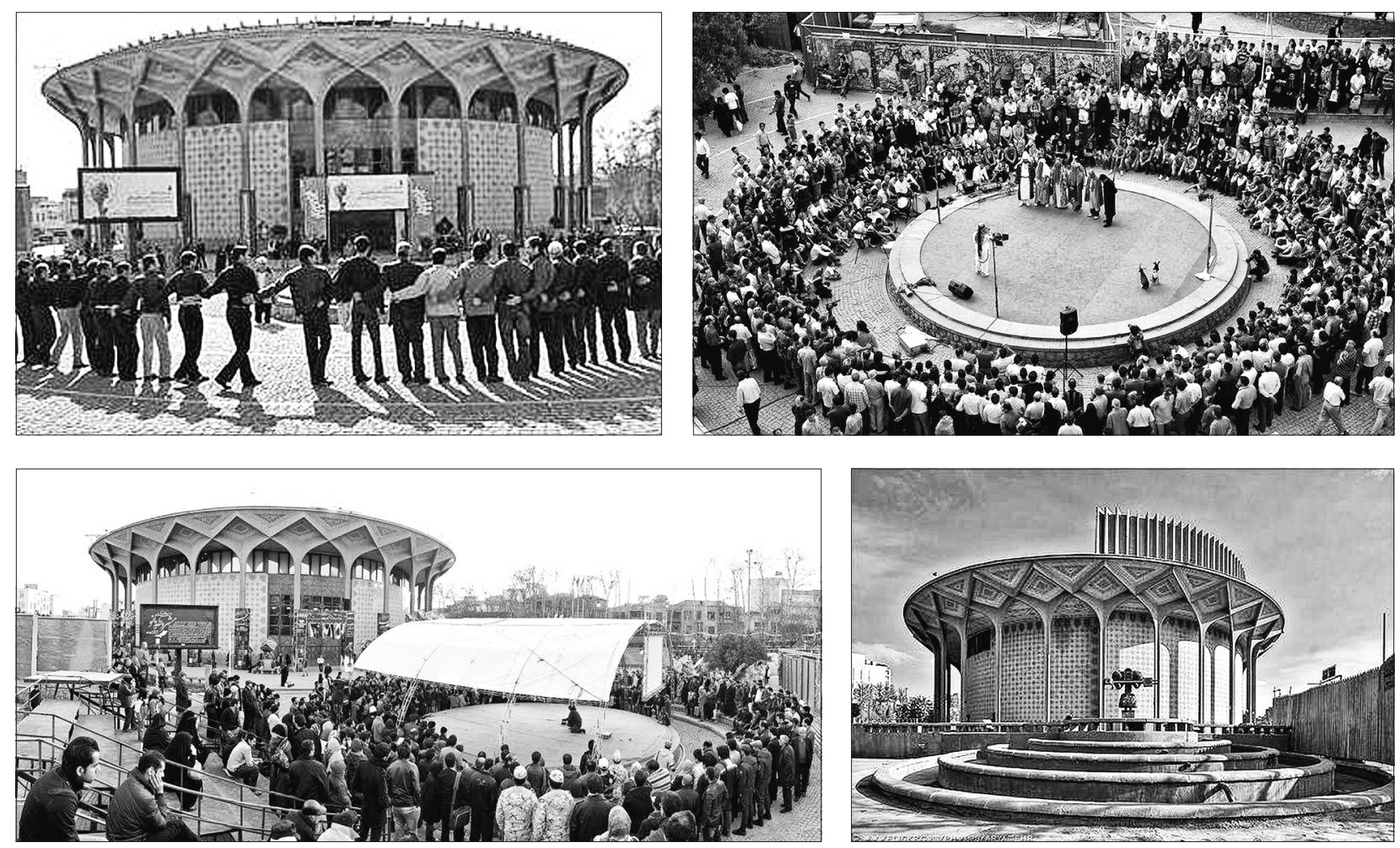

Figure 1. Tehran City Theatre

tation study by which the conceptual and theoretical investigation were done on this subject, such that the researcher could present conceptual and theoretical definitions of each variable (Hafeznia, 2006) and use previous methods and studies results in the research. Survey method is considered as the most common research method in human sciences and its prominent property is use of questionnaire tool in data collection. In this study, the researcher gave respondents several items in form of questionnaire, so all of them answered to similar questions. These items measure research variables and final analysis is done based on the results obtained from variables relationships. Statistical population of this research includes all citizens resident in the district 11. Kokaran equation (Fanni, 2009) was used to determine sampling volume. According to formula, 525 questionnaires were distributed among respondents that the information obtained from 480 questionnaires was analyzable.

\section{Findings}

\section{City Theatre and leisure}

To test research hypotheses, research variables including feeling of happiness, leisure and life satisfaction were investigated. Results of questionnaires distributed among citizens based on Table 3 and Figure 2 indicate that 35.4 percent of citizens go watching theatre to the City Theatre and 19.9 percent of them select entertainments like cafes and City Theatre restaurants for their leisure. It can be said that locating at Vali-e-Asr crossroad; City Theatre has played an important role in residents' leisure and promoting the quality of citizens' life. Visiting numbers of City Theatre also indicate that how much this collection has tied to citizens' life. Also, statistics show that during a week, 40.5 percent of citizens visit the City Theatre three times or more; this can emphasize on the importance of this art collection in citizens' leisure.

Table 3. City Theatre and leisure

\begin{tabular}{|l|c|c|l|c|c|}
\hline $\begin{array}{l}\text { Entertainments like cafes and } \\
\text { restaurants }\end{array}$ & Numbers & Percent & $\begin{array}{l}\text { Visiting numbers of City } \\
\text { Theatre during a week }\end{array}$ & Numbers & Percent \\
\hline Watching theatre & 192 & 35.4 & One time & 100 & 32.3 \\
\hline Optimum use of their time & 111 & 23.8 & Two times & 131 & 27.3 \\
\hline Gathering resorts and meeting friends & 85 & 20.9 & Three times & 102 & 21.3 \\
\hline Entertainments like cafes, restaurants & 92 & 19.9 & More than three times & 92 & 19.2 \\
\hline Total & 480 & 100 & Total & 480 & 100 \\
\hline
\end{tabular}




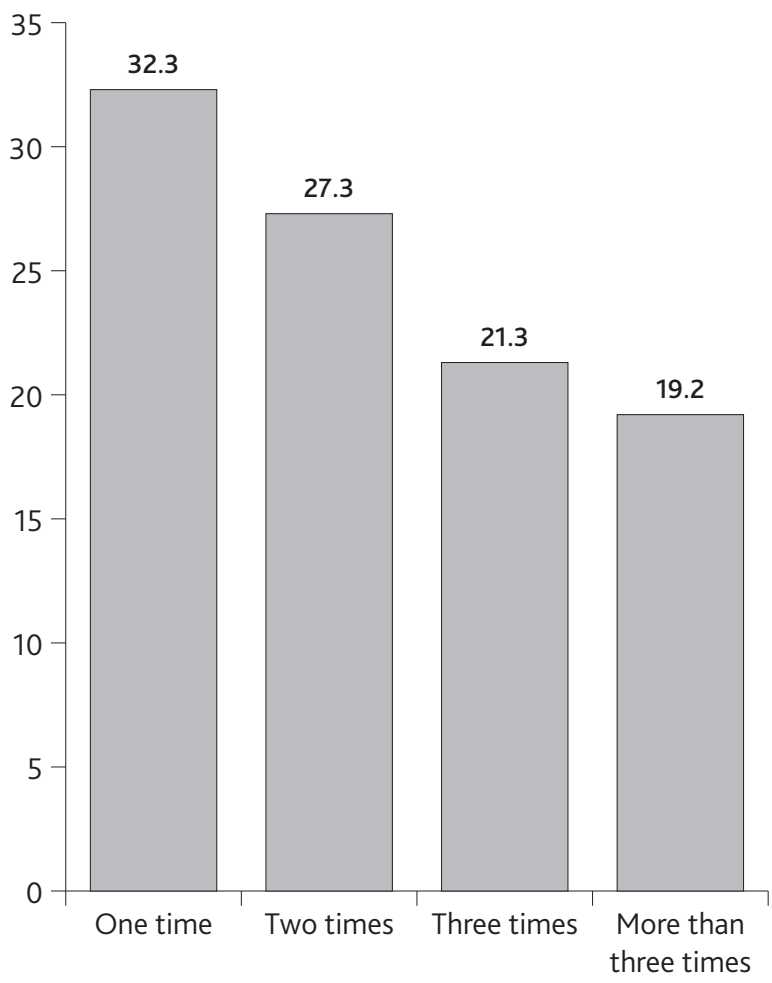

Figure 2. Entertainments like cafes, restaurants

\section{City Theatre and feeling of life satisfaction}

One of the mental dimensions of quality of life is the feeling of life satisfaction. In the present study, the feeling of life satisfaction was studied as a result of citizens' attendance in City Theatre Collection. The obtained results indicate that 37.3 percent of citizens which are equal to 179 persons of questioned statistical population visit the City Theatre in a large part of their life. This group includes more university students and cultural community; this shows the importance of the City Theatre in citizens' life. Also, in response to this question: in total, am I satisfied of my life; 17.7 percent have responded positively. Feelings of joy and happiness are subjective criteria of quality of life; in the present research it is decided to investigate its relationship with the City Theatre. The results of Table 4 indicate that 32.1 percent of citizens feel happi-

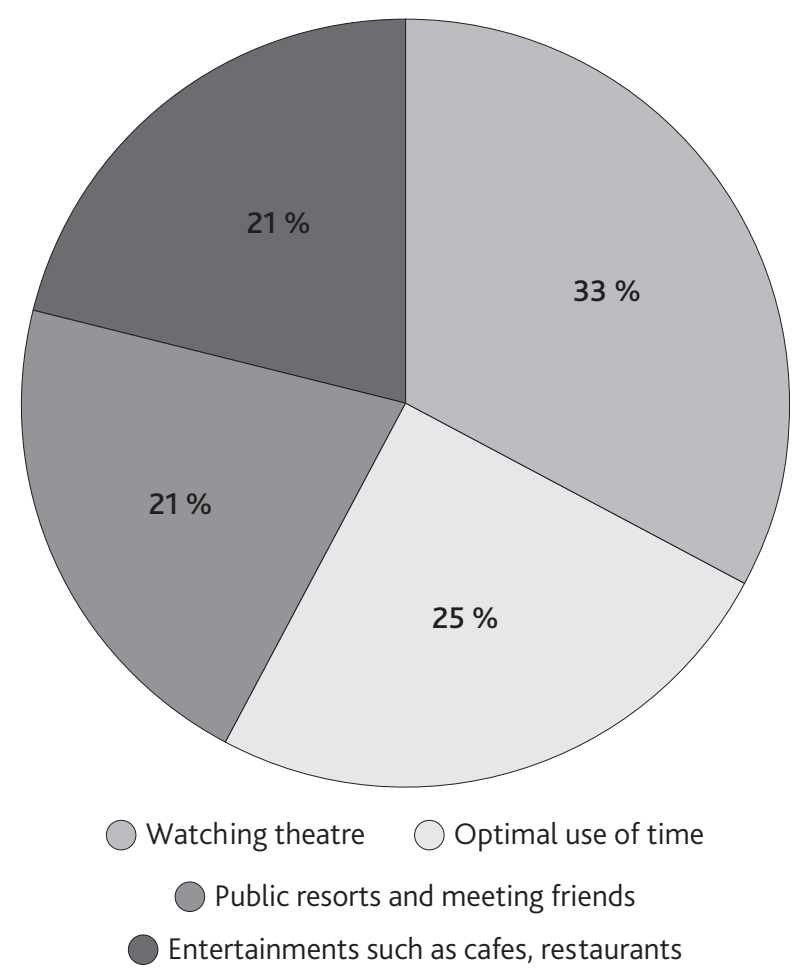

Figure 3. Visiting numbers of City Theatre during a week

ness and joy when they watch theatre; also 29.4 percent feel excitement when they are in the City Theatre collection and from its dynamism and vitality. In total, it can be said that the City Theatre plays an important role on citizens' joy and happiness.

\section{Inferential findings of the research}

Hypothesis Ho: It seems that the City Theatre has not played an important role in the promotion of subjective dimension of citizens' quality of life.

Hypothesis H1: It seems that the City Theatre has played an important role in the promotion of subjective dimension of citizens' quality of life. The following table shows that total model is significant. Generally in this table, if the significant level of $\mathrm{f}$ statistic is small (less than 0.05), independent varia-

Table 4. The feeling of satisfaction and happiness from life

\begin{tabular}{|l|c|c|l|c|c|}
\hline The feeling of satisfaction from life & Numbers & Percent & The feeling of happiness and joy & Numbers & Percent \\
\hline $\begin{array}{l}\text { Visiting the City Theatre includes a } \\
\text { large part of my life }\end{array}$ & 179 & 37.3 & I enjoy watching theatre & 154 & 32.1 \\
\hline $\begin{array}{l}\text { Availability of the City Theatre meet } \\
\text { a part of my needs }\end{array}$ & 156 & 32.5 & $\begin{array}{l}\text { I am very excited to be at } \\
\text { City Theatre Complex }\end{array}$ & 141 & 29.4 \\
\hline $\begin{array}{l}\text { The City Theatre located near my } \\
\text { residential place }\end{array}$ & 60 & 12.5 & $\begin{array}{l}\text { Elapsed times in the City Theatre } \\
\text { are the moments combined with } \\
\text { happiness }\end{array}$ & 97 \\
\hline Totally I am satisfied from my life & 85 & 17.7 & $\begin{array}{l}\text { I like the City Theatre complex more } \\
\text { than any other places }\end{array}$ & 88 & 18.3 \\
\hline Total & 480 & 100 & Total & 480 & 100 \\
\hline
\end{tabular}


Table 5. Investigating the significance of the City Theatre in the promotion of subjective dimension of citizens' quality of life

\begin{tabular}{|l|r|r|r|r|r|}
\hline Model & Sum of Squares & Df & Mean Square & \multicolumn{1}{c|}{ F } & \multicolumn{1}{c|}{ Sig } \\
\hline Regression & 6.225 & 5 & 1.112 & 406.137 & 0.008 \\
\hline Residual & 0.731 & 244 & 0.003 & & \\
\hline Total & 6.846 & 249 & & & \\
\hline
\end{tabular}

Adjusted R Square:/862

Table 6. Investigating the significance of the City Theatre in citizens' life satisfaction

\begin{tabular}{|l|r|r|r|r|r|}
\hline Model & Sum of Squares & Df & Mean Square & \multicolumn{1}{c|}{ F } & \multicolumn{1}{c|}{ Sig } \\
\hline Regression & 1.221 & 5 & 0.247 & 879.264 & 0.004 \\
\hline Residual & 0.058 & 244 & 0.001 & & \\
\hline Total & 1.401 & 249 & & & \\
\hline
\end{tabular}

Adjusted R Square:/847

Table 7. Investigating the significance of the City Theatre in citizens' happiness and joy

\begin{tabular}{|l|r|r|r|r|r|}
\hline Model & Sum of Squares & Df & Mean Square & \multicolumn{1}{c|}{ F } & Sig \\
\hline Regression & 3.241 & 5 & 0.333 & 912.239 & 0.025 \\
\hline Residual & 0.070 & 244 & 0.045 & & \\
\hline Total & 2.221 & 249 & & & \\
\hline
\end{tabular}

Adjusted R Square:/689

Table 8. Investigating the significance of the City Theatre in citizens' leisure

\begin{tabular}{|l|r|r|r|r|r|}
\hline Model & Sum of Squares & Df & Mean Square & \multicolumn{1}{c|}{ F } & Sig \\
\hline Regression & 6.352 & 5 & 0.289 & 743.146 & 0.016 \\
\hline Residual & 0.46 & 244 & 0.076 & & \\
\hline Total & 3.471 & 249 & & & \\
\hline
\end{tabular}

Adjusted R Square:/753

bles can explain clearly the alterations of dependent variables. If this value is greater than 0.05 , independent variables do not explain the alterations of dependent variables. "Adjusted R square" is also an amount of variance in the dependent variables that is explained by the independent variables.

According to Table 5, it is observed that the value of $\mathrm{F}$ is equal to 406.137 significance of 0.008 and since the significance level has been less than 0.05 , then the model is significant.

According to Table 6, it is observed that the value of $\mathrm{F}$ is equal to 879.264 significance of 0.004 and since the significance level has been less than 0.05 , then the model is significant.

According to Table 7 , it is observed that the value of $F$ is equal to 912.239 significance of 0.025 and since the significance level has been less than 0.05 , then the model is significant.

According to Table 8, it is observed that the value of $F$ is equal to 743.146 significance of 0.016 and since the significance level has been less than 0.05 , then the model is significant.

\section{Conclusion}

Creating a dynamic cultural space by taking advantage of social capabilities and the promotion of participation opportunities in the gathering life requires an understanding of space and its multi-faceted look of designers and urban planners in this regard. The quality of life with the same level of access to valuable subjective and objective opportunities through both public and private area is accessible. Spaces such City Theatre with their collective cultural performance can be a powerful and useful context for urban economy, strengthening social-cultural communications, creating security and trust in urban area, social control, increasing mental sensitivities and supplying emotional balance, strengthening aesthetic sensitivities, socialization and acculturation that affect the promotion of the quality of citizens' life. If this building was brought to the depth and inside the park, park becomes a beginning to enter the theater; and so the park was more alive and effective and social interaction was increased and hierarchy to reach the theatre formulated. These results can help in policies evaluation, ranking places, organizing management strate- 
gies and urban planning and facilitate understanding prioritization of social issues for planners and urban management in order to promote the quality of citizens' life. In total, from the factors effective on the success of gathering cultural spaces in the promotion of the quality of citizens' life, a proper geometric position, adjacency to coherent and consistent axis, diversity of social-cultural function for space users, attendance of memorable elements can be pointed.

\section{Acknowledgements}

This article was derived from master's thesis in architectural engineering titled Design of art \& cultural complex with sustainable principles approach (spatial co-thinking in the contemporary context), presented by Behnam Ghasemzadeh with the supervision of Dr. Sahar Toofan in faculty of art and architecture, Islamic Azad University of Tabriz.

\section{References}

Abbaszadegan, M. 2005. Social- psychological dimensions of urban spaces. International journal of engineering sciences 16. Iran University of Science \& Technology.

Bakhtiar Nasrabadi, A., Bakhtiar N., Hassan A., Bakhtiar Abadi, A. 2011. An analysis of socio petal urban space and its relationship with citizenship behavior. Journal of applied sociology 43, 101-114.

Cerulo, K. A. 2002. Cultural in mind: toward a sociology of culture and cognition, Routledge, London and New York.

Charkhian, M., Daneshpour, S. A. H. 2009. Investigating the components of respondent designing public spaces. Journal of geography and planning 30, 53-85.

Daneshpour, S. A. H., Charkhian, M. 2007. Public spaces and factors affecting on collective life. Journal of Bagh Nazar 7, 19-28.

Eiser, C. 2004. Children with Cancer the Quality of Life, University of Sheffield, Lawrence Erlbaum Associates Publishers, London.

Epley, R. D., Menon, M. 2008. A Method of Assembling Cross-sectional Indicators into a Community Quality of Life. Social Indicators Research 88 (2), $281-296$.

Fani, Z. 2009. Dimensional survey of city cultural geography; Case study: districts 1 and 12 of Tehran city. Journal of human geography research 68, 37-54.

Faraji Molaei, A., Azimi, A., Ziari, K. 2010. Dimensions analysis of quality of life in urban areas of Iran. Journal of research and urban planning 2, 1-16.

Fazeli, N. 2012. Culture and the city; Cultural turning in urban discourses relying on Tehran city studies, first edition, Tisa publication, Tehran, Iran.
Gharab, N. 2001. The effects of urban environment on human alienation. Journal of urban management 8 , 84-93.

Ghasemzadeh, B. 2012. Designing art and cultural complex with the trend of sustainable bases (cothinking in the contemporary context), Master thesis, Islamic Azad University, Tabriz branch, Iran.

Ghasemzadeh, B. 2013. Cross- Traditional Boundaries of Urban Plannung. Analele UniversităNii din Oradea - Seria Geografie 1, 85-80.

Ghasemzadeh, B. 2013. Cultural Spaces and Urban Identity (Integrating Modern State of the Art in Cultural Spaces). International Journal of Architecture and Urban Development 3 (1), 57-62.

Ghasemzadeh, B., Toofan, S. 2013. Investigating spatial balance in the distribution of cultural users applying share changing model; Case study: district 9 of Tehran city. Journal of Spatial and sustainable development 7, 14-25.

Ghiasvand, E. 2009. The effect of social capitals on the quality of life of residents of urban neighborhoods. Consulting engineers journal 45, 22-27.

Ghorbani, R., Teimouri, R. 2010. An analysis of the role of urban parks on the promotion of the quality of urban life using Seeking-escaping pattern, Case study: urban parks in Tabriz. Journal of human geography research 72, 47-62.

Golkar, K. 2007. The concept of quality of vitality in urban design. Journal of Safe 44, 66-75.

Hafeznia, M. R. 2006. An introduction on research method in human sciences. Samt publication,Tehran, Iran.

Hjinejad, A., Rafieian, M., Zamani, H. 2011. Investigating and ranking the factors effective on citizens' satisfaction from the quality of life environment; Case study: comparison of old and new textures of Shiraz city. Journal of human geography research 77 , 129-143.

Ibrahim, M., Chung, W. 2003. Quality of Life of Residents Living near Industrial Estates in Singapore. Social Indicators Research 61(2), 203-225.

Imani Jajarmi, H. 2001. The size of city and the quality of social relationship. Journal of urban management, 8, 106-111.

Jajarmi, K., Kalteh, E. 2006. Measuring the status of indicators of the quality of life in the city in terms of citizens view; Case study: Gonbad Ghabous. Journal of geography and development 8, 5-18.

Kaffashi, M. 2008. The effect of urban facilities on citizenship culture; Case study: district 8 of Tehran. Sociology journal of Islamic Azad University Ashtian branch 13, 87-120.

Kamp, I. V., Leidelmeijer, K., Marsman, G., Hollander., A. de 2003. Urban environmental quality and human well-being: Towards a conceptual framework 
and demarcation of concepts; a literature study. Landscape and Urban Planning 65, Issues 1-2, 5-18.

Kakavand, E., Barati, N., Aminzadeh Gohari, B. 2013. Comparative assessment of citizen's mental visualization and city maker means the quality of urban environment, Case study: Qazvin old texture. Journal of Bagh Nazar 25, 101-112.

Kashanijoo, K. 2010. Recognition of theoretical approaches toward urban public spaces. Journal of Hoviat shahr 6, 95-106.

Khadem Alhosseini, A., Mansourian, H., Sattari, M. H. 2010. Measurement of subjective quality of life in urban neighborhoods; Case study: Nourabad city, Lorestan province. Journal of geography and environmental studies 3, 45-60.

Khastoo, M., Saeedi Rezvani, N. 2010. The factors affecting on vitality of urban spaces. Journal of Hoviat shahr 6, 63-74.

Kokabi, A., Pourjafar, M. R., Taghvaie A. A. 2005. Planning the quality of urban life in urban centers; definitions and indicators. Journal of urban inquiries 12, 6-13.

Kokabi, A. 2007. Criteria for assessment of the quality of urban life in urban centers. Journal of Hoviat shahr 1, 75-86.

Lee, Y. J. 2008). Subjective quality of life measurement in Taipei. Building and Environment, 43 (7), 12051215.

Lennard, S. H. C., Lennard H. L. 1984. Public Life in Urban Places, Godlier, Southampton.

May, A. 1996. Information Technology in Urban Planning, Routledge, London.

Mirmoghtadaei, M. 2009. Criteria of measuring the possibility of formation, registration and transferring collective memories in the city; case study of Tehran. Journal of fine art 37, 5-16.

Mohammadi, J., Izadi, M. 2013. An analysis on cultural development level in Isfahan city using factor analysis. Journal of urban and regional studies and research 16, 89-104.

Moradi, A. 2010. Need assessment of cultural spaces development; Case study: Najafabad city in the year 2008. Journal of research in curriculum 27, 53-78.

Mousavi, M. N., Hassani, M., Manouchehri M. 2013. Analysis of citizens' social capital and its effect on the quality of the studied life: neighborhoods of Miandoab city. Journal of human geography research 45th edition - 4, 197-220.
Mukherjee, R. 1989. The Quality of Life Valuation in Social Research. New Delhi: Sage.

Naghsh consulting engineers 2008. Critique of contemporary architecture in Iran, first edition. Publications of architecture and urbanism study and research center, Tehran, Iran.

Nejat, S. 2008. The quality of life and its measurement. Iranian Professional journal of epidemiology (fourth edition) - 2, 57-62.

Noghani, M., Asgharpour, M., Ahmad R, Safa, S., Kermani, M. 2008. The quality of citizens' life and its relationship with social capital in Mashhad city. Journal of social science 1, 111-140.

Pakzad, J. 2001. Expertise culture and popular culture. Journal of urban management 8, 32-41.

Parsi, H. R. 2002. Recognizing the content of urban spaces. Journal of fine art 11, 41-49.

Piran, P. 2001. Urban culture. Journal of urban management 8, 6-17.

Profect, M., Power, G. 1992. Planning for urban quality, London.

Rabbani Khorasgani, A., Kianpour, M. 2007. The proposed model for measurement of the quality of life; Case study: Isfahan city. Journal of department of literature and human sciences 58/59, 67-108.

Rafieian, M., Razavi, H. 2010. Promotion of the quality of urban environment using design-oriented planning approach : City Theatre and around it. Journal of human science school-and space planning and Spatial (fourteenth edition) - 2, 269-287.

Schalock, R. L. 2004. The concept of quality of life: what we know and do not know. Journal of intellectual disability research 48(3), 203-16.

Tweed, C., Sutherland, M. 2007. Built cultural heritage and sustainable urban development. Landscape and urban planning 83, 62-69.

United Nations Population fund 2007. State of World Population 2007, Unlishing the Potential of Urban Growth, New York, UNFPA.

Ventegots, M., Jovvj. N. 2003. Quality of Life Theory: An Integrative Theory of the Global Quality of Life Concept. The Scientific World Journal 3, 1030-1040.

Yazdani, M., Lvasani, M. 2010. Gathering space; The realization of civil life: analysis of success factors in City Theatre forecourt. Scientific and promotion journal of Manzar second edition 7, 42-45. 